\title{
Satisfaction with Diabetes Services at Primary Care Level, Khartoum State, Sudan
}

\author{
Siham Ahmed Balla, ", Kamil Mirghani Ali Shaaban", Haiedr Abu Ahmed Mohamed", \\ Sulaf Ibrahim Abdelaziz ${ }^{2}$, Siddik Mohamed Ahmed Shaheen ${ }^{3}$ \\ ${ }^{1}$ Department of Community Medicine, Faculty of Medicine, University of Khartoum, Khartoum, Sudan \\ ${ }^{2}$ Department of Medicine, Faculty of Medicine, University of Khartoum, Khartoum, Sudan \\ ${ }^{3}$ Department of Econometrics and Social Statistics, Faculty of Economic \& Social Studies, University of Khartoum, Khartoum, Sudan
}

Email address:

semam44@yahoo.com (S. A. Balla),kamilshaaban@gmail.com (K. M. A. Shaaban), dr.hyder2008@yahoo.com (H. A. A. Mohamed),drsa3@yahoo.com (S. I. Abdelaziz), siddikshaheen@rocketmail.com (S. M. A. Shaheen) ${ }^{*}$ Corresponding author

\section{To cite this article:}

Siham Ahmed Balla, Kamil Mirghani Ali Shaaban, Haiedr Abu Ahmed Mohamed, Sulaf Ibrahim Abdelaziz, Siddik Mohamed Ahmed Shaheen. Satisfaction with Diabetes Services at Primary Care Level, Khartoum State, Sudan. American Journal of Health Research. Vol. 4, No. 5, 2016, pp. 127-133. doi: 10.11648/j.ajhr.20160405.13

Received: July 22, 2016; Accepted: August 24, 2016; Published: September 24, 2016

\begin{abstract}
Background: Patients' satisfaction is an important source of information about outcome quality of care. The objective was to measure satisfaction with diabetes services provided to diabetic patients attending primary care health centres compared to specialized diabetes centres in Khartoum state, Sudan. Methods: A cross sectional study was carried targeting 712 diabetic patients randomly selected from 40 primary care health centres and three specialized diabetes centres in Khartoum State. A structured questionnaire was used included patients` characteristics and three point Likert scale to assess satisfaction. Ethical approval was obtained by informed consent from the patients. Data managed by statistical package for social science version 20. Factor analysis was carried to extract latent components of the scale. Multivariate analysis of variance tested the difference in satisfaction between primary care health centres and specialized diabetes centres at an acceptable level of significance less than 0.05 . Results: The proportion of patients satisfied with diabetic services in primary health care centres was significantly low compared to specialized diabetes centres, $113(24.5 \%)$ and 145 (57.8\%) respectively, $\mathrm{P}=0.001$. The mean satisfaction scores in primary care health centres and specialized diabetes centres were $1.85 \pm 0.23$ and $2.12 \pm 0.33$ respectively, $\mathrm{P}=0.001$. Five factors were extracted from the satisfaction scale which contributed by $56.76 \%$ to the total variance. The mean satisfaction scores were significantly lower in primary care health centres compared to specialized diabetes centres regarding consultation session, technical capacity and referral, information and counseling and general satisfaction. Conclusion: Satisfaction with diabetes services was low in primary care health centres in Khartoum State. Capacity building regarding diabetes services at primary care level is recommended.
\end{abstract}

Keywords: Satisfaction, Diabetes Services, Factor Analysis, Multivariate, Primary Health Centres, Khartoum

\section{Introduction}

Patients' satisfaction is considered an important source of information about the quality of care as a consumer assessment. It reflects the health plans, health systems and the process of care, and it could be useful if carried out following the service encounter $[1,2]$.

Emphasizing the role of the patients and their rights to be exposed to information and treatment plans are important elements of quality of care and patients' satisfaction [3]. Patient satisfaction with diabetes services is indirectly assessing the quality of the health care system [4].

Globally, WHO reports the majority of the 346 million diabetic individuals are living in low- and middle-income countries (LMIC) [5]. In Middle East North Africa (MENA) region, the prevalence of diabetes is $10.9 \%$ with $11.3 \%$ projected prevalence at year $2025[6,7]$.

In Sub-Saharan African (SSA) countries, type 1 and type 
11 diabetes are increasing where health system has the opportunity for reform $[8,9]$.

Diabetes mellitus (DM) and impaired glucose intolerance (IGT) rates in Northern Sudan emerged as a public health concern in 1992 when the prevalence was $3.4 \%$ and $2.9 \%$ respectively [10]. The trend of hospital admission rates of diabetic patients in Sudan was increasing during the last few years [11].

World Diabetes Foundation (WDF) supported and financed health systems with several diabetes control projects in Sudan [12]. The support included development of guidelines and protocols for diabetes management and training materials for primary care level [12]. These efforts should have an effect on patients satisfaction as far as it measures the outcome of diabetes care at primary level. In the era of diabetes epidemic and the increasing trend of the disease in the country, health care at primary level has to be adequate and satisfying the needs of diabetic patients. Little evidence is available in Sudan regarding diabetic patients' satisfaction with care at the level of primary care especially in Khartoum State. The aim of this study was to measure the level of satisfaction with diabetes services among diabetic patients attending health centres (HCs) in Khartoum State with comparison to diabetic patients attending specialized diabetes centres (SDCs).

\section{Material and Method}

\subsection{Study Design}

This was a cross sectional descriptive study carried in Khartoum State.

\subsection{Study Site}

Khartoum State consists of seven localities with a total area of 22,736 square kilometers. It is the most populated state in Sudan, its population is about 5,414,618 and the growth rate is 2.66 [13].

\subsection{Population and Sampling}

The study population was adult diabetic males and females attending 40 health centres (HCs), 25 governmental (Gov.HCs) and 15 non-governmental (Non-Gov.HCs) and three specialized diabetes centres (SDCs). The selection criteria of the patients were; age 18 years and above and the duration of diabetes was not less than 2 years at the time of the study. The study included diabetic patients attended the health centres at least twice during last six months prior to the study. Patients with Diabetic Keto-acidosis (DKA), coma, pregnant women and acute hypoglycemia were excluded.

There is a little literature about patients' satisfaction in developing countries compared to the high volume of patients satisfaction researches that are published in developed countries [14]. A study in Egypt had shown that $23.6 \%$ of diabetic patients were satisfied with primary care [15]. This proportion was used as the anticipated value for sample size calculation.
A ready-made Altman's Nomogram was used for sample size calculation of the diabetic patients [16]. The anticipated proportion of satisfaction was $\mathrm{P} 1=23.6 \%$, and the researchers estimated an increased difference of interest at 10\%, P2 $=33$. $6 \%$. The standard difference (SD) was calculated by the following formula [16].

$$
\mathrm{SD}=\frac{p_{1}-p_{2}}{\sqrt{p^{\wedge}\left(1-p^{\wedge}\right)}}
$$
0.2 .

Where $\mathrm{p}^{\wedge}=\mathrm{P}_{1}+\mathrm{P}_{2} / 2=0.35$, therefore; SD approximate Using Altman`s Nomogram at the power $80 \%, \alpha$ error $=$ $0.05, \mathrm{SD}=0.2$, the sample size was 712 diabetic patients. The sample size was divided according to attendance rates at the study centres using probability proportional sampling (PPS).

\subsection{Data Collection Tool and Method}

A structured questionnaire was used for exit interview of diabetic patients. It included the socioeconomic and demographic profiles of the patients and three point Likert scale. The scale reflected the receipt of diabetes services and satisfaction. It was adapted from published literature to suit local Sudanese context [17-23]. It covered satisfaction with consultation session, technical capacity and referral, information and counseling, insulin demonstration and general satisfaction.

The patient questionnaire was pretested on 71 diabetic patients attending $10 \%$ of the health centres. The data obtained from the pretest was tested for construct and content validity and reliability by correlations between items and split half reliability at Cronbach's Alpha more than 0.7. Accordingly, the questionnaire was adjusted using the following criteria: 1) items correlations below 0.3 were excluded, 2) items which poorly performed in reliability tests were removed (less than 0.7 ), 3) negative questions were rephrased to positive ones and 4) questions of missing values more than $5 \%$ were removed. Therefore, the final scale of satisfaction with diabetes services (26SDS) was reduced from 31 to 26 items.

\subsection{Data Analysis}

Data managed by statistical package for social science (SPSS) version 20, revised for missing values, consistency and cleaned. Patients' characteristics were presented with descriptive statistics. Factor analysis was carried out to investigate the dimensionality of the scale and extract the latent components. Kaiser-Meyer-Olkin $(\mathrm{KMO})>0.5$ and Bartlett's Test $<0.01$ were checked to satisfy factor analysis. Eigen value $>1$ and coefficients above 0.3 were chosen.

Reliability of extracted factors and its contribution to the variance were presented. Pearson correlation was carried for the extracted components before running multivariate analysis of variance (MANOVA). The level of significance was chosen at less than 0.05 . 


\subsection{Ethical Considerations}

Ethical clearances were obtained from ethical committees in the faculty of Medicine -University of Khartoum and Khartoum State Ministry of Health. Confidentiality of patients' information was maintained. Written consent was obtained from the patients preceded by full explanation of the study objectives, risks and benefits.

\section{Results}

The diabetic patients in the study had the mean age of $54.72+10.9$ years and $79.7 \%$ been in the age group 35-65 years. Female to male ratio was $2: 1$. Seventy seven percent of the patients were educated. Retired or not working patients were $71.6 \%$. More than half of the patients $(54.6 \%)$ had monthly income ranging from 1000 to 2000 Sudanese Geneh [Table 1].

Table 1. Characteristics of diabetic patients attending study centres, Khartoum State, Sudan 2013.

\begin{tabular}{|c|c|c|c|c|}
\hline \multicolumn{2}{|c|}{ Characteristics of diabetic patients } & \multirow{2}{*}{$\begin{array}{l}\text { HCs }(n=461) \mathbf{N} \\
17\end{array}$} & \multirow{2}{*}{$\begin{array}{l}\text { SDCs }(n=251) N \\
13\end{array}$} & \multirow{2}{*}{$\begin{array}{l}\text { Total }(n=712) \mathbf{N}(\%) \\
30(4.2 \%)\end{array}$} \\
\hline & 20-35 Years & & & \\
\hline Age* & $>35-65$ Years & 370 & 198 & $568(79.7 \%)$ \\
\hline & $>65$ Years & 74 & 40 & $114(16.0 \%)$ \\
\hline \multirow{2}{*}{ Sex } & Male & 203 & 81 & $284(39.9 \%)$ \\
\hline & Female & 258 & 170 & $428(60.1 \%)$ \\
\hline \multirow{2}{*}{ Marital status } & Married & 418 & 242 & $660(92.7 \%)$ \\
\hline & Not married & 43 & 9 & $52(7.3 \%)$ \\
\hline Education & Educated & 354 & 194 & $548(77.0 \%)$ \\
\hline \multirow{2}{*}{ Occupation } & Not working & 313 & 197 & $510(71.6 \%)$ \\
\hline & Working & 148 & 54 & $202(28.4 \%)$ \\
\hline \multirow{3}{*}{ Monthly income ${ }^{\#}$} & Less than 1000 SDG & 171 & 96 & $267(37.5 \%)$ \\
\hline & $1000-2000 \mathrm{SDG}$ & 242 & 147 & $389(54.6 \%)$ \\
\hline & More than 2000 SDG & 48 & 8 & $56(7.9 \%)$ \\
\hline
\end{tabular}

* Mean age is $54.72 \pm 10.9$ years. Min 20 years: Max 90 years. \#Expenditure /day (n=707), 40.47 \pm 18.4 SDG. Min 8 SDG: Max 150 SDG

Satisfaction with diabetes services was measured by 26 item scale (26SDS) using three point Likert Scale; $1=$ dissatisfied $2 `=$ Fair $3=$ Satisfied. The cut-off point used for satisfaction was 2 scores and more. The proportion of diabetic patients who were satisfied with diabetes services in
HCs was significantly low compared to SDCs, $24.5 \%$ and $57.8 \%$ respectively, $(\mathrm{P}=0.001)$ [Table 2]. ANOVA test resulted in mean satisfaction score significantly low in $\mathrm{HCs}$ compared to SDCs; $1.85 \pm 0.23$ versus $2.12 \pm 0.33$ respectively, $(\mathrm{p}=0.001)$ [Table 2].

Table 2. Proportions of diabetic patients who are satisfied with diabetes care in study centres.

\begin{tabular}{llll}
\hline Satisfaction & HCs $(\mathbf{n}=\mathbf{4 6 1}$ patients) & SDCs (n=251 patients) & Test statistics* \\
\hline Satisfied & $113(24.5 \%)$ & $145(57.8 \%)$ & $x^{2} 77.818$ \\
Dissatisfied & $348(75.5 \%)$ & $106(42.2 \%)$ & df 2 \\
\hline
\end{tabular}

*ANOVA: $\mathrm{F}(1,710)=164.489 \mathrm{P}=0.001$ partial eta $=0.19$. Mean satisfaction score in $\mathrm{HCs}=1.85+0.23$. Mean satisfaction score in $\mathrm{SDCs}=2.12 \pm 0.33$

Satisfaction scale of diabetic patients with diabetes care at study centres was examined by principal component analysis (PCA) to extract the main latent components in the scale (factors). Five factors were extracted that contributed by $56.76 \%$ to the total variance. The five factors are: consultation session, technical capacity and referral, information and counseling, insulin demonstration and general satisfaction [Table 3]. In general, all study centres, had shown small proportions of diabetic patients satisfied with insulin demonstration, and information and counseling services, $13 \%$ and $14.3 \%$ respectively, [Fig 1].

Table 3. Factor analysis (FA) of satisfaction with diabetes care scale (26SDS)*.

\begin{tabular}{|c|c|c|c|c|c|c|}
\hline Satisfaction Scale & F1 & F2 & F3 & F4 & F5 & \% variance and Cronbach's Alpha \\
\hline The doctor listen to me well when am complaining & 0.834 & & & & & \multirow{2}{*}{$\%$ variance $=2.44 \%$} \\
\hline The doctor is caring about my complains and my questions & 0.832 & & & & & \\
\hline The consultation time was adequate to present all my complains & 0.873 & & & & & \multirow{2}{*}{ Alpha $=0.950$} \\
\hline The consultation time was adequate to present all my questions and queries & 0.872 & & & & & \\
\hline The doctor examine my chest and abdomen & & 0.521 & & & & \multirow[b]{3}{*}{$\%$ variance $=7.73 \%$} \\
\hline the doctor measured my blood pressure & & 0.370 & & & & \\
\hline The doctor examined my feet & & 0.668 & & & & \\
\hline The doctor referred me to care foot center & & 0.638 & & & & \multirow{3}{*}{ Alpha $=0.700$} \\
\hline the doctor referred me to eye clinic & & 0.693 & & & & \\
\hline The doctor gave me a follow up appointment & & 0.311 & & & & \\
\hline The doctor explain to me some facts about causes of diabetes & & & 0.787 & & & \multirow{2}{*}{$\%$ variance $=11.07 \%$} \\
\hline The doctor explain to the complications of diabetes & & & 0.772 & & & \\
\hline
\end{tabular}




\begin{tabular}{|c|c|c|c|c|c|c|}
\hline Satisfaction Scale & F1 & F2 & F3 & F4 & F5 & \% variance and Cronbach's Alpha \\
\hline The doctor explain to me the normal and random blood sugar levels & & & 0.661 & & & \\
\hline The doctor advise me to diet plan to control my diabetes & & & 0.660 & & & \\
\hline The doctor advise me to reduce my weight to control my diabetes & & & 0.632 & & & Alpha $=0.858$ \\
\hline The doctor advise me to do physical activities to control my diabetes & & & 0.659 & & & \\
\hline The doctor demonstrate to me how to store insulin & & & & 0.967 & & $\%$ variance $=7.12 \%$ \\
\hline The doctor demonstrate to me how to care for the injection sites & & & & 0.970 & & Alpha $=0.990$ \\
\hline I completely trust the diabetic services in the health center & & & & & 0.583 & \\
\hline The diabetic services in the health center of high quality & & & & & 0.671 & \\
\hline The fees of diabetic services is acceptable & & & & & 0.632 & $\%$ variance $=8.40 \%$ \\
\hline The drugs usually available at each of my visits to the health center & & & & & 0.607 & \\
\hline The prices of the drugs are acceptable & & & & & 0.674 & \\
\hline The investigations are available at each of my visits to the health center & & & & & 0.596 & Alpha $=0.732$ \\
\hline The prices of investigations are acceptable & & & & & 0.533 & \\
\hline
\end{tabular}

*Principal component analysis conducted with factor loadings $>0.3$, Varimax rotation with Kaiser normalization and Eigen value $>1$. Contribution to the total variance was $56.76 \% . F 1$ : Consultation session,F2: Technical capacity and referral,F3: Information and counseling,F4: Insulin demonstration,F5: General satisfaction.

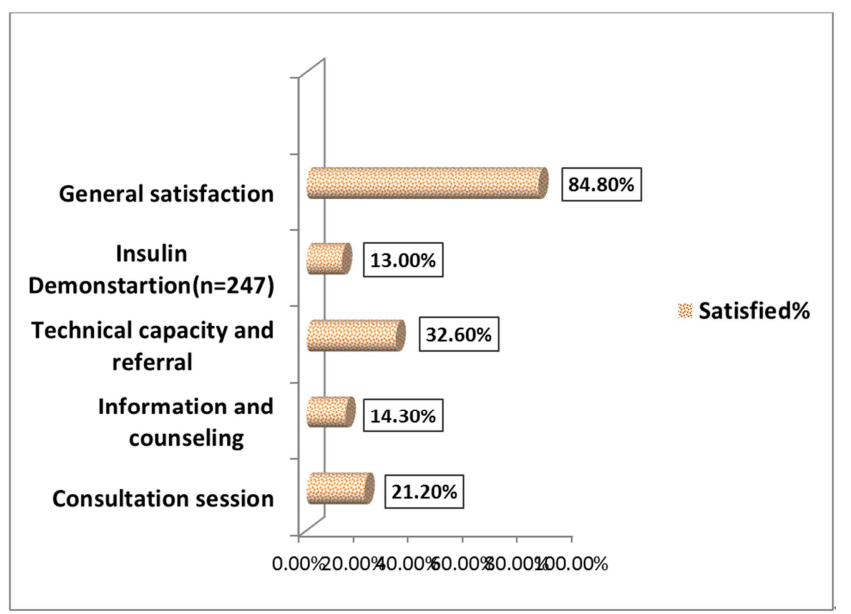

Fig 1. Proportion of diabetic patients satisfied with diabetes care in study centres as per components of satisfaction scale, Khartoum State 2013.

Pearson correlations was carried prior to MANOVA and showed adequate significant correlation between the factors at statistical level $<0.01$.

Running general linear model (GLM) using MANOVA showed significance difference between the types of study centres with respect to the combined five factors in 26SDS. Wilk`s Lambda $=0.505, F(10,1410)=57.34, P=0.001$, partial $\eta^{2}=0.29$. The model effect size was strong and showed that $29 \%$ of the difference in total satisfaction of diabetic patients was related to the types of the study centres.

The differences in factors of satisfaction were explained in post hoc Univariate Tests:

1. Consultation session: satisfaction of diabetic patients in SDCs was significantly high compared to Gov.HCs and Non-Gov.HCs. $F(2,709)=321.52, P=0.001$, partial $\eta^{2}$ $=0.48$. The mean score was higher among diabetic patients attending the SDCs $(\mathrm{M}=10.3)$ compared to Gov.HCs and Non-Gov.HCs $(\mathrm{M}=7.0 \quad \& \quad \mathrm{M}=8.0$ respectively).

2. Technical capacity and referral: satisfaction of diabetic patients in SDCs was significantly high compared to Gov.HCs and Non-Gov.HCs. $F(2,709)=12.99, P$ $=0.001$, partial $\eta^{2}=0.04$. The mean score was higher among diabetic patients attending the SDCs $(\mathrm{M}=13.6)$ compared to Gov.HCs and Non-Gov.HCs $(\mathrm{M}=12.6$ \& $\mathrm{M}$ $=11.5$ respectively).

3. Information and counseling: satisfaction of diabetic patients in SDCs was significantly high compared to Gov.HCs and Non-Gov.HCs. $F(2,709)=43.48, P$ $=0.001$, partial $\eta^{2}=0.11$. The mean score was higher among diabetic patients attending the SDCs $(\mathrm{M}=13.5)$ compared to Gov.HCs and Non-Gov.HCs $(\mathrm{M}=11.1 \& \mathrm{M}$ $=11.6$ respectively).

4. General satisfaction: satisfaction of diabetic patients in SDCs was significantly high compared to Gov.HCs and Non-Gov.HCs. $F(2,709)=8.07, P=0.001$, partial $\eta^{2}=$ 0.02 . The mean score was higher among diabetic patients attending the SDCs $(\mathrm{M}=18.4)$ compared to Gov.HCs and Non-Gov.HCs (M=17.3 \& $\mathrm{M}=17.2$ respectively).

5. Insulin demonstration: insignificant difference was observed between types of study centres regarding satisfaction of diabetic patients. $F(2,709)=1.404, P$ $=0.246$, partial $\eta^{2}=0.004$.

\section{Discussion}

The 26 items scale of satisfaction with diabetes services (26SDS) produced five latent components of satisfaction; the consultation session, the information and counseling, the technical capacity and referral, the insulin demonstration and the general satisfaction. These components contributed to $56.76 \%$ of the total variance that consistent with the satisfaction scale of Turkish women [24]. The Turkish scale focused on three factors; the administration and the office procedures, the communication and the care coordination and comprehensiveness of services [24]. Contribution to the total variance in psychometric scales varies according to the inherent characteristics of the scale. The 26SDS could be generalized to all diabetic patients, males and females for diabetes services at primary care level while the Turkish scale was limited to women in Erzurum in Turkey making the inherit comparison difficult. The satisfaction with diabetes care in this study was unique, presented multi-dimensional scale compared to satisfaction with primary care in Catalonia 
health survey [25]. The latter product was one-dimensional scale representing a health system factor that contributed by $64 \%$ to the variance. A study in England at primary care showed variation in contribution to the variance among the scale factors; waiting for appointment; accessibility and communication skills [26]. The differences in contribution to the variance in the different studied scales could be due to the sample size, different populations, different services and the items in the scales.

In general, in this study, satisfaction of diabetic patients with diabetes care in HCs was lower compared to SDCs. The overall mean difference in satisfaction score was significantly higher in favor of SDCs. Nineteen percent of the change in patients ' satisfaction was due to the type of centre, partial $\eta^{2}$ $=0.19$. The health centres in Khartoum State had shown low structural quality of care regarding diabetes services compared to the specialized diabetes centres [27]. Structures of health settings, receiving the required care and the proper treatment, are factors increasing patients' satisfaction that vice versa reflected on adherence of the patients to treatment and positively correlated with glycemic control [28, 29]. It was found that high quality of primary care services was correlated positively with self-rates of patients about their good health [30].

In this study, the satisfaction of diabetic patients at primary care level significantly low regarding the consultation session, the technical capacity of medical doctors, the information and counseling, and the general satisfaction. In India, satisfaction with services in community health centres, primary care centres and tribal health settings was high $[31,32]$. The generalization of the study population in the Indian studies and inclusion of all outpatients reflected the difference in patients satisfaction. The low patients' satisfaction in this study could be due to the poor health centres structures [27]. In the United Arab Emirates, the overall satisfaction with primary health care was average regarding six domains; accessibility, continuity, humaneness, comprehensiveness, health education and effectiveness [33].

Emirates citizens are reflecting high socioeconomic class attending high quality health settings in well-off country compared to primary care setting in Khartoum State where diabetic patients were less satisfied with services.

Satisfaction of diabetic patients regarding consultation sessions was lower compared to a study carried in Poland [34]. Patients' satisfaction, adherence to self-care measures and positive health care outcomes increased positively with adequate consultation at the health setting $[35,36]$.

A small proportion of insulin dependent patients (13.0\%) out of 247 were satisfied with insulin injection techniques and caring of injection sites that demonstrated by medical doctors in the study centres. This is in lines with the situation in developing countries. The injection technique survey had shown that a small percentage of diabetic patients were provided with education about insulin injection in China and Pakistan [37, 38] Insulin injection demonstration is commonly and not routinely provided by the nurses in Sudan compared to Pakistan that commonly provided by the physicians [37].

Insulin injection demonstration is an important technique to ensure the effectiveness and efficiency of diabetes treatment. In the injection technique survey, over one third of patients did not receive any instructions about insulin injection technique [39]. Half of diabetic patients in the United States complained of care providers who don't care about their questions regarding pain and bruising as consequences of insulin injection [40].

1. Limitations: The satisfaction scale for diabetic patients could not be applicable for other chronic diseases at primary care level.

2. Conclusion: Satisfaction of diabetic patients with services in health centres was significantly low compared to specialized diabetes centres in Khartoum State. The consultation sessions, the technical capacity and referral, the information and counseling, and the general satisfaction had shown significantly low mean scores in HCs. The proportions of diabetic patients satisfied with insulin demonstration and information and counseling services were low. Training of care providers at the health centres on diabetes management, communication skills and insulin injection demonstration is recommended.

3. Competing interest: All authors declared no competing interest

4. Authors' contributions: SAB developed the proposal, carried data collection, managed and analyzed data and drafted the article. KMAS assisted in development of the tool, carried literature search and revised of the article. SIA assisted in data collection and carried literature search. SMAS assisted the revision of data management and analysis. HAAM: revised the article for intellectual content and the citing of references

5. Acknowledgements: the first author acknowledged the smart collaboration given by staff in the department of local health system in Khartoum State.

\section{References}

[1] Zaslavsky AM. Using hierarchical models to attribute sources of variation in consumer assessments of health care. Statist Med 2007; 26: 1885-900.

[2] Murti A, Deshpande A, Srivastava N. Service Quality, Customer (Patient) Satisfaction and Behavioural Intention in Health Care Services: Exploring the Indian Perspective. Journal of Health Management 2013; 15 (1): 29-44.

[3] Rahmqvist M, Bara Ana-C. Patient characteristics and quality dimensions related to patient satisfaction. Int J Qual Health Care. 2010; 22 (2): 86-92. Barr DA, Vergun P, Barley SR. Problems in using patient satisfaction data to assess the quality of care provided by primary care physicians. JCOM 2000; 7 (9): 19-28.

[4] Barr DA, Vergun P, Barley SR. Problems in using patient satisfaction data to assess the quality of care provided by primary care physicians. JCOM 2000; 7 (9): 19-28. 
[5] WHO. Diabetes Fact sheet N 312. [online]. 2011 Aug [Accessed 2011 Aug]; Available from URL: http://www.who.int/mediacentre/factsheets/fs312/en/.

[6] IDF. Diabetes Atlas 6th ed. [online]. 2013 [Accessed 2013]; Available from URL: http://www.idf.org/diabetesatlas.

[7] Guariguata L, Whiting D, Hambleton I, Beagley J, Linnenkamp U, Shaw J. Global estimates of diabetes prevalence for 2013 and projections for 2035. Diabetes research and clinical practice 2014; 103 (2): 137-49.

[8] Mbanya JCN, Motala AA, Sobngwi E, Assah FK, Enoru ST. Diabetes in sub-Saharan Africa. The Lancet2010 June; 375 (9733): 2254-66.

[9] Beran D, Yudkin JS. Diabetes care in sub-Saharan Africa. The Lancet 2006 Nov; 368 (9548): 1689-95.

[10] FMOH. Guidelines for diagnosis and management of diabetes mellitus in adults and children. In: Department NCDs. Khartoum: Marafe for advertise services; 2008.

[11] FMOH. Annual Statistic Report for 2010. Department of Health Statistics (Khartoum); 2010.

[12] KSMOH. Report on training of medical doctors and educators in Sudan. In: Directorate of NCDs (Khartoum) 2010.

[13] CBS. 2008 population projection for 2011. In: Central Bearu of Statistics (Khartoum)2010.

[14] Bernhart MH, Wiadnyana I, Wihardjo H, Pohan I. Patient satisfaction in developing countries. Social science \& medicine 1999; 48 (8): 989-96.

[15] Koura M, Khairy A, Abdel-Aal N, Mohamed H, Amin G, Sabra A. The role of primary health care in patient education for diabetes control. The Journal of the Egyptian Public Health Association 2000; 76 (3-4): 241-64.

[16] Stewart A. Basic statistics and epidemiology: a practical guide. New York: Radcliffe Publishing Oxford; 2010. p. 90-3.

[17] Asch SM, Kerr EA, Keesey J, Adams JL, Setodji CM, Malik $\mathrm{S}$, et al. Who is at greatest risk for receiving poor-quality health care?. New Engl J Med 2006; 354 (11): 1147-56.

[18] Escarce JJ, Kapur K, Solomon MD, Mangione CM, Lee PP, Adams JL, et al. Practice Characteristics and HMO Enrollee Satisfaction with Specialty Care: An Analysis of Patients with Glaucoma and Diabetic Retinopathy. Health Serv Res 2003; 38 (4): $1135-55$.

[19] Idvall E, Hamrin E, Sjöström B, Unosson M. Patient and nurse assessment of quality of care in postoperative pain management. Quality and Safety in Health Care 2002; 11 (4): 327-34.

[20] Pouwer F, Snoek FJ. Patients' Evaluation of the Quality of Diabetes Care (PEQD): development and validation of a new instrument. Quality and Safety in Health Care 2002; 11 (2): $131-6$.

[21] Rocha KB, Rodríguez-Sanz M, Pasarín MI, Berra S, Gotsens M, Borrell C. Assessment of primary care in health surveys: a population perspective. The European Journal of Public Health 2012; 22 (1): 14-9.

[22] Campbell JL, Ramsay J, Green J. Age, gender, socioeconomic, and ethnic differences in patients' assessments of primary health care. Quality in Health Care 2001; 10 (2): 90-5.
[23] Salomon L, Gasquet I, Mesbah M, Ravaud P. Construction of a scale measuring inpatients' opinion on quality of care. Int $\mathbf{J}$ Qual Health Care 1999; 11 (6): 507-16.

[24] Erci B, Çiftçioğlu S. Psychometric evaluation of the primary health-care satisfaction scale in Turkish women. Int J Qual Health Care 2010; 22 (6): 500-506.

[25] Rocha KB, Rodríguez-Sanz M, Pasarín MI, Berra S, Gotsens M, Borrell C. Assessment of primary care in health surveys: a population perspective. The European Journal of Public Health 2012; 22 (1): 14-9.

[26] Salisbury C, Wallace M, Montgomery AA. Patients' experience and satisfaction in primary care: secondary analysis using multilevel modelling. BMJ 2010; 341: c5004. Available from URL: http://www.ncbi.nlm.nih.gov/pmc/articles/PMC2954274/.

[27] Balla SA, Shaaban KMA, Abdelaziz SI, Abdeldafia NMA. Structural Quality of Diabetes Services at Primary Health Care in Khartoum State 2013: Health centres versus specialized diabetes centres. Medicine Science and Healthcare Journal 2015; 10 (8): 41-50. Available from URL: $\mathrm{http}$ ://oaspjournal.org/AllIssue/allissue.php/?jID=4\&vol=10\&i ssue $=8$.

[28] Barr DA, Vergun P, Barley SR. Problems in using patient satisfaction data to assess the quality of care provided by primary care physicians. JCOM 2000; 7 (9): 19-28.

[29] Alazri MH, Neal RD. The association between satisfaction with services provided in primary care and outcomes in Type 2 diabetes mellitus. Diabetic Medicine 2003; 20 (6): 486-90.

[30] Sung NJ, Markuns JF, Park KH, Kim K, Lee H, Lee JH. Higher quality primary care is associated with good self-rated health status. Family Practice 2013; 30 (5): 568-75.

[31] Kumari R, Idris M, Bhushan V, Khanna A, Agarwal M, Singh S. Study on patient satisfaction in the government allopathic health facilities of Lucknow district, India. Indian J Community Med 2009; 34 (1): 35-42.

[32] Chandwani HR, Jivarajani PJ, Jivarajani HP. Community perception and client satisfaction about the primary health care services in a tribal setting of Gujarat-India. Internet $\mathrm{J}$ Health 2009; 9 (2). Available from URL: https://ispub.com/IJH/9/2/8795.

[33] Margolis SA, Al-Marzouqi S, Revel T, Reed RL. Patient satisfaction with primary health care services in the United Arab Emirates. Int J Qual Health Care 2003; 15 (3): 241-249

[34] Marcinowicz L, Rybaczuk M, Grebowski R, Chlabicz S. A short questionnaire for measuring the quality of patient visits to family practices. Int J Qual Health Care 2010; 22 (4): 294301 .

[35] Zolnierek KBH, DiMatteo MR. Physician communication and patient adherence to treatment: a meta-analysis. Med Care 2009; 47 (8): 826-83.

[36] Matthews SM, Peden AR, Rowles GD. Patient-provider communication: Understanding diabetes management among adult females. Patient Education and Counseling 2009; 76 (1): $31-7$.

[37] Sheikh MA, Hakeem R, Asar F, Shaikh AH. Diabetes education and care in a developing country: Observations from Karachi, Pakistan. Primary care diabetes 2015; 9 (1): 4853. 
[38] De Coninck C, Frid A, Gaspar R, Hicks D, Hirsch L, Kreugel $\mathrm{G}$, et al. Results and analysis of the 2008-2009 Insulin Injection Technique Questionnaire survey. Journal of Diabetes 2010; 2 (3): 168-79.

[39] Saltiel-Berzin R, Cypress M, Gibney M. Translating the Research in Insulin Injection Technique Implications for
Practice. The Diabetes Educator 2012; 38 (5): 635-43.

[40] Rubin RR, Peyrot M, Kruger DF, Travis LB. Barriers to Insulin Injection Therapy: Patient and Health Care Provider Perspectives. The Diabetes Educator 2009; 35 (6): 1014-22. 